\title{
Alternative Somatic Cell Count Traits as Mastitis Indicators for Genetic Selection
}

\author{
Y. de Haas, ${ }^{\star 1}$ W. Ouweltjes, $†$ J. ten Napel, $†$ J. J. Windig, $†$ and G. de Jong ${ }^{*}$ \\ ${ }^{*}$ NRS, Animal Evaluation Unit, PO Box 454, NL-6800 AL Arnhem, the Netherlands \\ †Animal Sciences Group, PO Box 65, NL-8200 AB Lelystad, the Netherlands
}

\begin{abstract}
The aim of this study was to define alternative traits of somatic cell count (SCC) that can be used to decrease genetic susceptibility to clinical and subclinical mastitis (CM and SCM, respectively). Three kinds of SCC traits were evaluated: 1) lactation-averages of SCC, 2) traits derived from the proportion of test-day SCC above 150,000 cells $/ \mathrm{mL}$, and 3) patterns of peaks in SCC. Genetic parameters for these SCC traits and their genetic correlation with CM and SCM were estimated; CM and SCM were scored as binary traits. Two data sets (A and $\mathrm{B}$ ) depending on $\mathrm{CM}$ recording were available. After editing, subset A contained 28,688 lactations from 21,673 cows in 394 herds. Subset B contained 56,726 lactations of 30,145 cows in 272 herds. Variance components for sire and permanent animal effects were estimated. Estimated heritabilities for all mastitis traits were around 0.03. Heritabilities for SCC traits ranged from 0.01 for patterns of peaks in SCC to 0.13 for lactation-average SCC. Genetic correlations between SCC traits and CM or SCM ranged from 0.55 to 0.93 for $\mathrm{CM}$ and from 0.55 to 0.98 for SCM. High genetic correlations were estimated between CM and SCC averaged over $250 \mathrm{~d}$ in milk (0.87), and between SCM and presence of test-day SCC $>150,000$ cells $/ \mathrm{mL}(0.98)$ in subset $\mathrm{A}$. In subset $\mathrm{B}$, a high genetic correlation was estimated between $\mathrm{CM}$ and an SCC peak with a quick recovery (0.93) and between SCM and SCC averaged between 151 and $400 \mathrm{~d}$ (0.95). Partial genetic correlations were calculated to investigate the additional information of the alternative SCC traits, compared with lactation-average SCC. They showed that some traits remain informative for $\mathrm{CM}$ and others for SCM. Therefore, use of information from a combination of different SCC traits may be more successful in improving overall udder health than the traditional single SCC measure.
\end{abstract}

Received June 19, 2007.

Accepted February 29, 2008.

${ }^{1}$ Corresponding author: Haas.Y@nrs.nl
Key words: somatic cell count, clinical mastitis, genetic selection

\section{INTRODUCTION}

Several studies have shown that selection for production alone causes negative effects on udder health (Heringstad et al., 2003). This has caused a growing interest in broadening national selection indices to include functional traits such as health and reproduction (Miglior et al., 2005). In most national indices summarized by Miglior et al. (2005), log-transformed SCC (i.e., SCS) was the only trait contributing to udder health. However, the estimated genetic correlation between SCS and mastitis is only moderate $(\approx 0.7)$, but ranges from 0.3 to 0.9 (Mrode and Swanson, 1996). Therefore, it could be worthwhile to explore the potential of alternative traits derived from SCC. These traits may provide additional information to decrease the genetic susceptibility to clinical and subclinical mastitis (CM and SCM, respectively).

Alternative SCC traits have been suggested. Testday records for SCC may be analyzed individually (Heuven, 1987; Reents et al., 1995) or may be described on a lactation level (Detilleux et al., 1997; Schepers et al., 1997; De Haas et al., 2003). Examples of suggested traits are 1) proportions of test-day SCC above or below certain thresholds, 2) directions and rates of change in test-day SCC, 3) number of days until SCC reaches an upper or lower threshold, 4) differences between observed SCC and SCC expected under healthy conditions, 5) areas under (parts of) the lactation curve of SCC, 6) rolling SCC averages, or 7) peaks in SCC.

In most countries, the lactation-average is an average of log-transformed test-day cell counts (Mark et al., 2002). However, a high test-day SCC will have a greater impact on the average if the test-day SCC are first averaged and then log-transformed. Genetic selection on lowering the log-transformed lactation-average SCC may therefore be more effective in decreasing mastitis incidence than genetic selection on lowering the lactation-average of log-transformed SCC. 
Another reason for looking at alternative SCC traits is that lactation-average SCC does not account for variation in source of an SCC surge. Although IMI explain most of the increases in SCC, other factors such as heat stress or the hormonal cycle of the cow also increase SCC (Wegner et al., 1976; Wever and Emanuelson, 1989). There is evidence that selection for lower SCC decreases mastitis incidence without weakening natural defenses (Rupp and Boichard, 2000; Nash et al., 2002). However, differentiation of SCC according to their potential source (e.g., IMI or other factors) can still be beneficial (Gengler and Mayeres, 2003). In the latter study, test-day SCC was weighted iteratively by an indicator function reflecting IMI likelihood. Gengler and Mayeres (2003) concluded that although their method was simple, it provided breeding values that better predicted mastitis resistance.

The objective of this study was to develop alternative SCC traits and to estimate their genetic relationship with CM and SCM. These alternative SCC traits take into account the length of the observed lactation-period, patterns of peaks in SCC, and indicators of excessive SCC.

\section{MATERIALS AND METHODS}

\section{Trait Definitions}

Analyzed udder health traits were CM and SCM. Both traits were scored as present (1) if in a lactation at least one case of $\mathrm{CM}$ or SCM, respectively, was recorded. Otherwise, they were scored as absent (0). Consequently, only the first case of CM and SCM within a lactation was taken into account. Cases of SCM were derived from test-day SCC and were defined as a transition from 2 consecutive SCC recordings below a certain threshold to one $\mathrm{SCC}$ recording above this threshold (Van den Borne et al., 2006). The thresholds were the same as used in the Dutch national milk recording: 150,000 cells $/ \mathrm{mL}$ for primiparous cows and 250,000 cells/mL for multiparous cows [NRS (Dutch Dairy Association), 2005]. Cell counts of healthy cows are below these thresholds during lactation, except between 5 and 14 DIM (De Haas et al., 2002). Therefore, there was no need to preadjust the test-day SCC recordings for stage of lactation.

Three sets of alternative SCC traits were defined as mastitis indicators for genetic selection. The first set consisted of SCC averaged over different periods of time during the lactation. The second set was derived from the proportion of excessive SCC records of all recorded test-days during the lactation. The third set corresponded to patterns of peaks in SCC (De Haas et al., 2004). These traits are described in more detail below.

Lactation-Average SCC. Most first cases of CM occur in the first weeks of lactation (Emanuelson et al., 1988; Barkema et al., 1998). Therefore, test-day SCC was averaged over different lactation lengths. Cell counts were averaged per lactation over the testday records up to $400,350,300,250,200,150$, and 100 DIM. The average SCC was then transformed to SCS with the following formula:

$$
\mathrm{SCS}=1,000+100 \times\left[{ }^{2} \log (\mathrm{SCC} / 1,000,000)\right] .
$$

The transformation resulted in SCS400, SCS350, SCS300, SCS250, SCS200, SCS150 and SCS100, respectively (Table 1). A minimum of 2,3 , and 4 SCC records were required to calculate SCS100, SCS150, and SCS200, respectively. At least 5 SCC records were required in the corresponding lactation periods to calculate SCS250, SCS300, SCS350, and SCS400. Missing values were assigned when these criteria were not met. By log-transforming the average SCC, a high testday SCC had a greater impact on the value of the SCS trait than when the average of log-transformed testday SCS was calculated as the SCS trait.

To compare the first vs. second part of the lactation, SCC was averaged over d 151 to 400 . This average was log-transformed (SCS151-400) if a cow had 2 or more SCC records between 150 and 400 DIM (Table 1).

The alternative lactation-averages of SCC were compared with a lactation-average SCS that is similar to the trait currently used in the Dutch breeding value estimation. Test-day SCC was first log-transformed using equation [1], and the average of all test-day SCS between 5 and 335 DIM was calculated (SCS335; Table 1). No criteria on the number of test-day recordings were set. This comparison can support or reject the hypothesis that a log-transformed average SCC is a more informative mastitis-indicator in genetic selection than the average of log-transformed test-day SCS.

Excessive Test-Day SCC. It was assumed that excessive test-day SCC originated from an IMI. Each test-day SCC was classified individually as a binary trait. A test-day SCC $>150,000$ cells/mL was registered as 1 ; otherwise, it was registered as 0 . The threshold of 150,000 cells $/ \mathrm{mL}$ was chosen based on the lowest threshold currently used by NRS to highlight animals with high SCC (NRS, 2005). No distinction was made between lactating primiparous and multiparous cows in the current study. Individual SCC records were not adjusted for the fluctuations due to DIM (i.e., the standard lactation curve of healthy cows; De Haas et al., 2002). The standard lactation curve only exceeds 150,000 cells $/ \mathrm{mL}$ in the first $14 \mathrm{DIM}$. Therefore, a test- 
Table 1. Number of lactation records with udder health and SCC traits, with their explanations, and their means in 2 data sets (A and B)

\begin{tabular}{|c|c|c|c|c|c|}
\hline \multirow[b]{2}{*}{ Trait } & \multirow[b]{2}{*}{ Definition } & \multicolumn{2}{|c|}{ No. of lactations } & \multicolumn{2}{|c|}{ Mean } \\
\hline & & A & $\mathrm{B}$ & A & $\mathrm{B}$ \\
\hline $\mathrm{CM}$ & Absence or presence of clinical mastitis $(0 / 1)$ & 28,688 & 56,726 & 0.109 & 0.104 \\
\hline SCS100 & Log-transformation of average test-day SCC up to $100 \mathrm{DIM}$ & 24,043 & 54,258 & 594.0 & 584.6 \\
\hline SCS150 & Log-transformation of average test-day SCC up to 150 DIM & 24,756 & 53,381 & 609.6 & 601.0 \\
\hline SCS200 & Log-transformation of average test-day SCC up to $200 \mathrm{DIM}$ & 25,268 & 51,966 & 622.8 & 614.8 \\
\hline SCS250 & Log-transformation of average test-day SCC up to 250 DIM & 25,605 & 50,460 & 634.7 & 626.8 \\
\hline SCS400 & Log-transformation of average test-day SCC up to $400 \mathrm{DIM}$ & 27,136 & 51,172 & 657.3 & 646.9 \\
\hline SCS151-400 & Log-transformation of average test-day SCC between 151 and $400 \mathrm{~d}$ & 26,980 & 50,804 & 666.8 & 659.5 \\
\hline SCS335 & Average of log-transformed test-day SCC up to 335 DIM & 28,688 & 56,726 & 626.4 & 617.7 \\
\hline Suspicion of IMI & Absence or presence of test-day SCC $>150,000$ cells $/ \mathrm{mL}(0 / 1)$ & 28,688 & 56,726 & 0.598 & 0.571 \\
\hline Extent of IMI & Proportion of test-day SCC $>150,000$ cells $/ \mathrm{mL}$ of all recorded test-days & 28,688 & 56,726 & 0.394 & 0.212 \\
\hline Severity of IMI & $\begin{array}{l}\text { Absence or presence of test-day SCC }>250,000 \text { cells } / \mathrm{mL} \text {, } \\
\text { within "suspected" group }(0 / 1)\end{array}$ & 17,170 & 32,178 & 0.680 & 0.678 \\
\hline P_ALL & Sum of environmental and contagious peaks & 28,621 & 56,487 & 0.264 & 0.224 \\
\hline
\end{tabular}

day SCC above 150,000 cells $/ \mathrm{mL}$ that occurs after 14 DIM was registered as 1 .

Four SCC traits were defined to describe the dynamics of SCC during lactation, based on excessive testdays. The hypothesis was that the dynamics differ between healthy and mastitic cows. The first SCC trait was referred to as "suspicion of IMI" and distinguished between presence (1) or absence (0) of a test-day SCC $>150,000$ cell $\mathrm{s} / \mathrm{mL}$ in a lactation. The second SCC trait was referred to as "extent of IMI" and was calculated as proportion of all recorded test-days in a lactation that were excessive. The third SCC-trait was referred to as "severity of IMI" and was only calculated for the "suspected" group. It expressed whether the cell count was moderately (0) or severely (1) increased, with a lower threshold at 250,000 cells $/ \mathrm{mL}$. The last SCC trait was "length of IMI" and was also calculated only within the "suspected" group. Length of IMI was defined as the number of test-day recordings during the longest streak of consecutive cell counts $>150,000$ cells $/ \mathrm{mL}$ (Table 1).

Patterns of Peaks in SCC. Patterns of peaks in SCC distinguished between lactations with short or long periods of increased SCC on the basis of recovery within 2 test-day records. Based on literature, upper and lower thresholds were used to define peaks. Healthy and recovered cows (i.e., low SCC) were assumed to have $<200,000$ somatic cells/mL (Dohoo and Leslie, 1991). Infected cows (i.e., high SCC) were assumed to produce $>500,000$ cells $/ \mathrm{mL}$ (Lam et al., 1997). Two different patterns of peaks in SCC were observed and classified. The first pattern was a quick increase in SCC followed by an immediate decrease in SCC. In other words, consecutive test-day SCC records had to be low-high-low (De Haas et al., 2004). This pattern is often associated with cases of CM caused by environmental pathogens (Smith and Hogan, 1993), and was therefore referred to as environmental pattern (P_ENV). The second pattern captured longer periods of increased SCC (i.e., one test-day with a low SCC followed by at least 2 test-days with high SCC). In other words, no recovery took place within 2 test-day recordings (De Haas et al., 2004). This pattern can often be associated with cases of CM caused by contagious pathogens (Fox and Gay, 1993), and was therefore referred to as contagious pattern (P_CONT).

The defined patterns (P_ENV and P_CONT) were analyzed both individually and combined into all patterns of peaks ( $\mathbf{P} \_$ALL) without specifying the kind of peak (Table 1). The 3 patterns, P_ENV, P_CONT, and P_ALL, were always counted per lactation. When a pattern did not fully match the criterion on the third test-day, this pattern was proportionally assigned to both P_ENV and P_CONT. For example, if a SCC of 300,000 cell $\mathrm{s} / \mathrm{mL}$ was recorded on the third test-day after a low and high SCC on the previous 2 test-days, this SCC pattern was then assigned for $2 / 3$ to $\mathrm{P}_{\text {ENNV }}$ and for $1 / 3$ to P_CONT.

Different threshold values were applied for patterns of peak than for excessive test-day SCC. This was because the traits were taken directly from other studies. Different thresholds were not modified to synchronize across traits to keep consistency of results from the current study with previous reports, and to analyze the effect of different kinds of traits with different thresholds as mastitis-indicators. 


\section{Available Data}

Two different data sets with cases of CM were available, each with a different way of recording cases of CM. Both data sets were analyzed and compared with assess the results, and to investigate the possibility of applying the results to the complete national database. The first data set (data set A) contained information from 396 Dutch herds with cases of CM recorded between July 1, 2004, and June 30, 2005. At least 50 milking cows were present at each participating farm. Information on CM was collected by NRS (Arnhem, the Netherlands) during the monthly milk recording. The milk-recording officers asked the farmers if a cow was mastitic on the day of milk recording, or if she experienced a case of CM in the period between the previous and current milk recording. This data set contained farmer-diagnosed CM, which might have introduced a possible bias caused by variation among farmers in diagnostic criteria. The data were not validated with bacteriological tests, but Lam et al. (1993) concluded that farmer subjectivity does not have a negative influence on the validity of farmer-diagnosed CM. Farmer-diagnosed CM, therefore, can be used as an information source on CM.

The second data set (data set B) contained information from 274 Dutch herds. Data of cases of CM were recorded between July 1, 1999, and January 1, 2006. The actual start and end date of the data recording varied among farms, depending on when a management information system was purchased and how long it was used on a farm. The farmers themselves collected information on (treatments of) $\mathrm{CM}$ and they allowed NRS to upload and use these data.

The complete history of the milk production recordings from all cows in the participating herds in data set A or data set B was available. A record included a cow identification number, herd number, date of calving, parity, test-date, test-day yields (kilograms of milk, fat, and protein) and SCC (in cells/mL). A pedigree file of all participating cows in either data set A or B was also available and contained the ancestry of 140,000 animals (approximately 124,000 cows and 16,000 bulls) back to 1908 . The pedigree record included also information on the date of birth and the breed of cows. The breed of the cow was subdivided into 2 main contributing breeds, with each having up to 9 classes $(0,1 / 8, \ldots, 8 / 8)$ depending on the degree of contribution.

\section{Data Editing}

Two subsets (A and B) with information on CM, SCM, and SCC traits were constructed from the original phenotypic records in the 2 different main data sets (A and B, respectively). When constructing subset $\mathrm{A}$, the aim was to include the maximum feasible number of lactations recorded during the study, and to avoid bias due to culling in early lactation. Therefore, each lactation that was recorded for at least one day during the experiment was included in the data set. The number of days at risk and in milk for each lactation was determined, requiring a start and end date. The start date was 1) calving date or 2) July 1, 2004, whichever occurred last. The end date was 1 ) last testdate in a lactation, 2) date of $400 \mathrm{~d}$ postpartum, or 3) June 30, 2005, whichever occurred first. Two variables were constructed to adjust for the variable lengths of days at risk between cows due to a fixed sampling period of udder health data: 1) subtraction of the end date from the start date resulted in the number of days at risk and in milk during the experiment for each individual lactation, and 2) number of days in milk at the start of the study was determined by subtracting the calving date from July 1, 2004. A zero was scored for dry lactations and for primiparous cows that were not yet in milk at the start of the study.

Data editing was done by excluding lactations 1 ) of fourth parity and higher, 2) with ages at first calving less than $640 \mathrm{~d}$, and 3) of cows with less than $75 \%$ Holstein-Friesian genes. Only test-day SCC recordings between 5 and 400 DIM, and only observations on CM between -15 and 400 DIM were included (Heringstad et al., 1997). For the analyses, a pedigree file was constructed based on sires and maternal grandsires (MGS) of cows in the data set. This file contained 2,168 AI bulls with 1,422 sires plus 1,268 MGS (of which 787 were also sires) and 265 unique sires of the sires or sires of the MGS. Cows with unknown pedigree and cows of sires with fewer than 5 offspring in the data set were deleted. The final subset A consisted of 28,688 lactations from 21,673 cows on 394 herds.

For subset B, the same criteria on parity, age at first calving, percentage of Holstein-Friesian genes, SCC recordings, $\mathrm{CM}$ observations, and number of offspring were applied as for subset A. The final subset B consisted of 56,726 lactations of 30,145 cows on 272 herds. The 2 variables for days at risk were not constructed for this data set, because all lactations were included from calving onwards. Only lactations that started at least 6 mo after the first case of CM was recorded in the on-farm computerized management information system were included. It was assumed that a farmer needed this period to adapt to using the system. This was also confirmed by frequency profiles, in which the proportion of cows with CM fluctuated a lot in the first 6 mo after installing the on-farm information system, and stabilized after that period. For the analyses, a 
pedigree file was constructed based on sires and MGS of cows in the data. This file contained 3,436 AI bulls with 2,446 sires plus 2,471 MGS (of which 1,791 were also sires) and 310 unique sires of the sires or sires of the MGS.

\section{Statistical Analyses}

(Co)variance components were estimated with a generalized linear mixed model using ASREML (Gilmour et al., 2006). Univariate analyses were carried out for CM, SCM, and SCC traits using a linear model. The model included random effects for sire and MGS and for cow [to account for the permanent animal effects (PERM) across repeated lactations]. The model used was

$$
\begin{gathered}
\mathrm{Y}=\mu+\text { fixed effects }+\mathrm{S}_{\text {sire }}+1 / 2 \mathrm{~S}_{\mathrm{mgs}} \\
+\mathrm{PERM}_{\text {animal }}+\mathrm{e} .
\end{gathered}
$$

The random sire and MGS effects were identified by the subscripts for sire and MGS $\left(\mathrm{S}_{\text {sire }}\right.$ and $\mathrm{S}_{\mathrm{mgs}}$, respectively) and therefore each animal in the pedigree obtained one estimate for the additive genetic effect. The 1/2 was included because the incidence matrix of MGS effects was laid over the matrix of sire effects. Therefore, both sire and MGS were estimated in only one component and if a bull had entries in the data as sire and MGS, the breeding value as MGS was equal to half the breeding value of a sire (Calus et al., 2005). The sire effects were linked using the relationship matrix, and were assumed to be normally distributed with $\operatorname{var}\left(\mathrm{S}_{\text {sire or mgs }}\right)=\sigma_{s}^{2}$. Permanent animal effects contained environmental effects common to different lactations and genetic effects not covered by sire and MGS such as a dam component, dominance, and Mendelian sampling terms. This was assumed to be normally distributed as well, with $\operatorname{var}\left(\mathrm{PERM}_{\text {animal }}\right)=\sigma_{E a}^{2}$.

Fixed effects included were an interaction between herd and year of calving (1,174 classes in subset $A$ and 1,647 classes in subset B), parity (with 3 classes), and month of calving (with 12 classes). Linear polynomials were included for age at calving, days at risk in subset $\mathrm{A}$, and only for age at calving in subset B.

Bivariate analyses were carried out to estimate correlations between CM, SCM, and SCC traits, using a linear model for all traits. Cows with missing values for SCM or SCC traits were still included in the analyses. Fixed effects were the same as mentioned for the univariate analyses. Combined linear and logistic models were also analyzed, in which either the udder health traits or the SCC traits were treated as categorical traits, and the other trait was assumed to be nor- mally distributed. The estimated genetic correlations were similar to those originating from the complete linear model. Therefore, only the estimated parameters from the complete linear model are shown. Univariate analyses were also carried out with a logistic model to account for the binary nature of the udder health traits. It was decided to present only the results from the linear models to stay in line with the bivariate results.

Genetic parameters were calculated from the estimated (co)variance components. The additive genetic variance was calculated by multiplying the sire variance by 4 . The phenotypic variance $\left(\sigma_{p}^{2}\right)$ was the sum of the sire variance multiplied by 1.25 , plus the permanent animal and residual variance. The factor 1.25 is explained by the fact that effects for both sire $\left[(1)^{2}=\right.$ 1 times the sire variance] and MGS $\left[(0.5)^{2}=0.25\right.$ times the sire variance] explained part of the total genetic variance (Calus et al., 2005). Heritabilities were calculated by division of additive genetic variances by phenotypic variances. The permanent animal effect between lactations was calculated by dividing $\sigma_{E a}^{2}$ by $\sigma_{p}^{2}$. Genetic, phenotypic, permanent animal, and error correlations were estimated using the corresponding variance and covariance components.

\section{Partial Genetic Correlations}

Partial genetic correlations were calculated to investigate whether the alternative SCC traits provided additional information for selection aiming to decrease genetic susceptibility to CM and SCM, compared with SCS335. A partial correlation is the correlation between any 2 of the variables if each were uncorrelated with the third variable (Lowry, 2007). In the current study, partial genetic correlations were calculated between an udder health trait (CM or SCM) and an alternative SCC trait, when taking into account SCS335. Following Lowry (2007), the partial genetic correlation of X (udder health) and Y (alternative SCC traits), with the effects of Z (SCS335) removed, was calculated as:

$$
r_{X Y \cdot Z}=\frac{r_{X Y}-\left(r_{X Z}\right)\left(r_{Y Z}\right)}{\sqrt{1-r_{X Z}^{2}} \sqrt{1-r_{Y Z}^{2}}} .
$$

\section{RESULTS}

\section{Descriptive Analyses}

In both subsets, approximately $11 \%$ of lactations had at least one case of CM (Table 1). Proportions of lactations with at least one case of SCM were $35 \%$ in subset A and $33 \%$ in subset B. The lactation-average 
Table 2. Heritabilities $\left(\mathrm{h}^{2}\right)$ and genetic variances $\left(\sigma_{\mathrm{a}}^{2}\right)$ with standard errors in parentheses, of udder health traits (clinical and subclinical mastitis) and several SCC traits ${ }^{1}$ in 2 data sets (A and B)

\begin{tabular}{|c|c|c|c|c|}
\hline \multirow[b]{2}{*}{ Trait } & \multicolumn{2}{|c|}{ Data set A } & \multicolumn{2}{|c|}{ Data set B } \\
\hline & $\mathrm{h}^{2}$ & $\sigma_{\mathrm{a}}^{2}$ & $\mathrm{~h}^{2}$ & $\sigma_{\mathrm{a}}^{2}$ \\
\hline Clinical mastitis & $0.03(0.01)$ & $0.002(0.001)$ & $0.02(0.01)$ & $0.002(0.000)$ \\
\hline Subclinical mastitis & $0.04(0.01)$ & $0.007(0.002)$ & $0.03(0.01)$ & $0.007(0.001)$ \\
\hline SCS100 & $0.09(0.01)$ & $1,563(266.1)$ & $0.08(0.01)$ & $1,864(258.4)$ \\
\hline SCS150 & $0.10(0.02)$ & $1,651(261.3)$ & $0.08(0.01)$ & $1,830(252.1)$ \\
\hline SCS200 & $0.12(0.02)$ & $1,636(252.7)$ & $0.10(0.01)$ & $1,997(261.7)$ \\
\hline SCS250 & $0.12(0.02)$ & $1,518(230.8)$ & $0.11(0.01)$ & $1,945(252.8)$ \\
\hline SCS300 & $0.13(0.02)$ & $1,526(224.9)$ & $0.12(0.02)$ & $2,044(255.2)$ \\
\hline SCS350 & $0.13(0.02)$ & 1,536 (223.6) & $0.12(0.02)$ & $2,026(250.3)$ \\
\hline SCS 400 & $0.13(0.02)$ & $1,515(220.0)$ & $0.12(0.02)$ & $1,986(245.6)$ \\
\hline SCS151-400 & $0.13(0.02)$ & $1,641(240.9)$ & $0.13(0.02)$ & $2,047(254.8)$ \\
\hline SCS335 & $0.12(0.02)$ & $1,567(228.6)$ & $0.12(0.01)$ & $1,712(211.5)$ \\
\hline Suspicion of IMI & $0.06(0.01)$ & $0.012(0.002)$ & $0.06(0.01)$ & $0.014(0.002)$ \\
\hline Extent of IMI & $0.08(0.02)$ & $0.007(0.001)$ & $0.11(0.01)$ & $0.008(0.001)$ \\
\hline Severity of IMI & $0.03(0.01)$ & $0.007(0.002)$ & $0.03(0.01)$ & $0.007(0.002)$ \\
\hline Length of IMI & $0.08(0.01)$ & $0.517(0.088)$ & $0.09(0.01)$ & $0.406(0.057)$ \\
\hline P_ALL & $0.04(0.01)$ & $0.010(0.002)$ & $0.05(0.01)$ & $0.009(0.002)$ \\
\hline P_ENV & $0.02(0.01)$ & $0.002(0.001)$ & $0.01(0.00)$ & $0.001(0.000)$ \\
\hline P_CONT & $0.04(0.01)$ & $0.004(0.001)$ & $0.04(0.01)$ & $0.004(0.001)$ \\
\hline
\end{tabular}

${ }^{1}$ See Table 1 for abbreviations and definition of the traits.

SCS did not differ much between the 2 subsets. The proportion of lactations with presence of SCC $>150,000$ cells $/ \mathrm{mL}$ was roughly $60 \%$ in both subsets. The average length of the longest streak of consecutive test-days with SCC above 150,000 cells/mL was slightly longer in subset A (1.84 test-days) than in subset B (1.57 testdays). The proportion of lactations with patterns of peaks in SCC was again similar in both subsets (Table 1).

All cows in subset A had information on both SCS150 and SCS100. This was, however, not the case in subset B. All herds in data set A participated in a study that required monthly milk recording, whereas this criterion was not set in data set $\mathrm{B}$. Consequently, the interval between 2 test-dates could range from 3 to $8 \mathrm{wk}$ (i.e., 21 to $56 \mathrm{~d}$ ) in data set $\mathrm{B}$, and criteria on number of test-days required to calculate the average were not always met.

\section{Univariate Analyses}

The heritability of CM and SCM was 2 to $4 \%$ (Table 2). Heritabilities for lactation-average SCS varied from 0.08 to 0.13 and increased with longer lengths of lactation. Heritability of SCS335 was 0.12 . The heritabilities of SCC traits describing the dynamics of SCC ranged from 0.03 to $0.11 \%$. Generally, the heritabilities of SCC traits were lower than estimates for lactation-average SCS, but greater than estimates for CM and SCM. Heritabilities for patterns of peaks in SCC were low (0.01 to 0.05$)$. Genetic variances were similar in both subsets for all alternative SCC traits, except for the lactation-average SCS. These were greater in subset $B$ than in subset A (Table 2).

\section{Bivariate Analyses}

Genetic correlations of $\mathrm{CM}$ were high with lactationaverages in subset A $(>0.80)$, and also with the patterns of peaks in SCC, especially in subset B (Table $3)$. Genetic correlations with lactation-average SCS over longer periods were greater for SCM $(>0.90)$ than for CM ( $>0.66)$, significantly in subset B. Correlations with traits describing the dynamics of SCC were also greater for SCM than for CM except for "severity of IMI." For P_ENV, genetic correlations were lower with SCM than with CM.

The genetic correlations between SCM and SCC traits did not differ substantially between subset A and $\mathrm{B}$ (Table 3). The genetic correlation between CM and SCS150 was much greater than the genetic correlation between CM and SCS151-400 in subset B (Table 3 ). In subset $\mathrm{A}$, both genetic correlations were about equally high. This seems to suggest that genetic selection on lower SCC during early lactation also decreases the occurrence of CM.

The estimated genetic correlations between $\mathrm{CM}$ and SCS335 were $0.64( \pm 0.08)$ and $0.80( \pm 0.08)$ in subsets A and $\mathrm{B}$, respectively. The estimated genetic correlation between SCM and SCS335 was $0.90( \pm 0.04)$ in subset $\mathrm{A}$, and $0.85( \pm 0.04)$ in subset $\mathrm{B}$. The estimated genetic correlation between CM and SCM was $0.79( \pm 0.10)$ in subset A, and $0.50( \pm 0.12)$ in subset $\mathrm{B}$. The genetic correlations between SCS335 and the alternative SCC 
Table 3. Genetic correlations, with their standard errors in parentheses, between clinical mastitis (CM) and subclinical mastitis (SCM), the currently used SCC trait $\left(\mathrm{SCS} 335^{1}\right)$ and several SCC traits ${ }^{1}$ in 2 data sets $(\mathrm{A}$ and $\mathrm{B})$

\begin{tabular}{|c|c|c|c|c|c|c|}
\hline \multirow[b]{2}{*}{ Trait } & \multicolumn{3}{|c|}{ Data set A } & \multicolumn{3}{|c|}{ Data set B } \\
\hline & $\mathrm{CM}$ & SCM & SCS335 & $\mathrm{CM}$ & SCM & SCS335 \\
\hline SCS100 & $0.77(0.07)$ & $0.70(0.09)$ & $0.91(0.03)$ & $0.71(0.08)$ & $0.67(0.08)$ & $0.94(0.02)$ \\
\hline SCS150 & $0.82(0.07)$ & $0.77(0.08)$ & $0.95(0.02)$ & $0.73(0.07)$ & $0.75(0.06)$ & $0.96(0.01)$ \\
\hline SCS200 & $0.84(0.07)$ & $0.84(0.06)$ & $0.97(0.01)$ & $0.72(0.07)$ & $0.81(0.05)$ & $0.97(0.01)$ \\
\hline SCS250 & $0.87(0.07)$ & $0.88(0.05)$ & $0.98(0.01)$ & $0.69(0.08)$ & $0.87(0.04)$ & $0.99(0.00)$ \\
\hline SCS300 & $0.86(0.07)$ & $0.91(0.04)$ & $0.99(0.00)$ & $0.67(0.08)$ & $0.89(0.04)$ & $0.99(0.00)$ \\
\hline SCS350 & $0.86(0.07)$ & $0.93(0.04)$ & $0.99(0.00)$ & $0.66(0.08)$ & $0.90(0.03)$ & $0.99(0.00)$ \\
\hline SCS400 & $0.85(0.07)$ & $0.94(0.04)$ & $0.99(0.00)$ & $0.66(0.08)$ & $0.91(0.03)$ & $0.99(0.00)$ \\
\hline SCS151-400 & $0.79(0.08)$ & $0.98(0.02)$ & $0.97(0.01)$ & $0.55(0.09)$ & $0.95(0.02)$ & $0.97(0.01)$ \\
\hline Suspicion & $0.75(0.10)$ & $0.98(0.02)$ & $0.95(0.02)$ & $0.60(0.09)$ & $0.94(0.02)$ & $0.95(0.02)$ \\
\hline Extent & $0.61(0.13)$ & $0.79(0.08)$ & $0.98(0.01)$ & $0.64(0.09)$ & $0.85(0.05)$ & $0.97(0.01)$ \\
\hline Severity & $0.62(0.15)$ & $0.73(0.10)$ & $0.89(0.06)$ & $0.88(0.07)$ & $0.70(0.09)$ & $0.89(0.04)$ \\
\hline Length & $0.69(0.11)$ & $0.89(0.05)$ & $0.95(0.02)$ & $0.62(0.09)$ & $0.88(0.04)$ & $0.95(0.01)$ \\
\hline P_ALL & $0.80(0.09)$ & $0.72(0.09)$ & $0.86(0.04)$ & $0.89(0.06)$ & $0.73(0.07)$ & $0.89(0.03)$ \\
\hline P_ENV & $0.66(0.09)$ & $0.55(0.14)$ & $0.74(0.09)$ & $0.93(0.06)$ & $0.68(0.10)$ & $0.90(0.06)$ \\
\hline P_CONT & $0.83(0.14)$ & $0.77(0.09)$ & $0.87(0.04)$ & $0.88(0.06)$ & $0.76(0.07)$ & $0.92(0.02)$ \\
\hline
\end{tabular}

${ }^{1}$ See Table 1 for abbreviations and definition of the traits.

traits were high in both subsets (Table 3), ranging from 0.74 to 0.99 . Near-unity genetic correlations were estimated between SCS335 and SCS300, SCS350, and SCS400.

\section{Partial Genetic Correlations}

In subset A, SCS200, SCS250, SCS300, SCS350, SCS400, and "extent of IMI" remained informative for CM (Table 4) when the effect of SCC335 was taken into account while calculating partial correlations. "Severity of IMI" and "length of IMI" appeared to have

Table 4. Partial genetic correlations between clinical mastitis (CM) and subclinical mastitis (SCM) and several alternative SCC traits ${ }^{1}$ in 2 data sets (A and B) if the correlations between the udder health traits (CM and SCM) and the SCC trait currently used in the breeding value estimation $\left(\mathrm{SCS} 335^{1}\right)$ were held constant

\begin{tabular}{lcccrr}
\hline & \multicolumn{2}{c}{ Data set A } & & \multicolumn{2}{c}{ Data set B } \\
\cline { 2 - 3 } \cline { 6 - 6 } Trait & CM & SCM & & CM & SCM \\
\hline SCS100 & 0.499 & -0.685 & & 0.219 & -0.980 \\
SCS150 & 0.682 & -0.576 & & 0.290 & -0.916 \\
SCS200 & 0.906 & -0.285 & & 0.236 & -0.674 \\
SCS250 & 0.990 & -0.072 & & -0.002 & -0.239 \\
SCS300 & 0.990 & 0.313 & & -0.248 & -0.033 \\
SCS350 & 0.990 & 0.676 & & -0.353 & 0.139 \\
SCS400 & 0.990 & 0.797 & & -0.353 & 0.310 \\
SCS151-400 & 0.616 & 0.981 & & -0.777 & 0.734 \\
Suspicion of IMI & 0.380 & 0.914 & -0.286 & 0.625 \\
Extent of IMI & -0.619 & -0.783 & & -0.196 & -0.172 \\
Severity of IMI & -0.007 & -0.351 & & 0.788 & -0.502 \\
Length of IMI & 0.108 & 0.249 & & -0.192 & 0.193 \\
P_ALL & 0.543 & -0.262 & & 0.820 & -0.357 \\
P_ENV & 0.294 & -0.403 & & 0.964 & -0.684 \\
P_CONT & 0.628 & -0.060 & & 0.843 & -0.398 \\
\hline
\end{tabular}

${ }^{1}$ See Table 1 for abbreviations and definition of the traits. no additional information compared with the currently used SCS335. For SCM, SCS151-400 and "suspicion of IMI" remained informative in subset A. In subset $\mathrm{B}$, presence of peaks in SCC remained informative for occurrence of CM (Table 4). Absence of high lactationaverage SCS in early lactation was informative for SCM.

\section{DISCUSSION}

\section{SCC Averages}

The estimated heritabilities for the standard lactation length (300 to 350 DIM) were estimated to be approximately $12 \%$, which is consistent with the heritability estimated for SCS335, and also with literature estimates (e.g., Mrode and Swanson, 1996). The heritabilities used in the Dutch breeding value estimation are estimated with a test-day model. Therefore, it is difficult to compare them with the estimates in the current study (along with the fact that the effects in both models differ). Overall, the heritabilities estimated in the current study tend to be lower than the heritabilities estimated in the Dutch breeding value estimation.

The estimated genetic correlations between SCS335 and SCS300, SCS350, or SCS400 were nearly equal, indicating that, genetically, they were the same traits. Therefore, defining the SCC trait as the log-transformation of a mean or a mean of the log-transformed test-day records did not have any effect on (co)variance estimations. However, in subset A, the genetic correlation between SCS300 (or SCS350) and CM was significantly greater than between SCS335 and CM. No sig- 
nificant difference was shown in subset B. This supported the hypothesis that records of high test-day SCC should be kept and should not be minimized with a log-transformation. This has been stated before from a biological point of view (Schepers et al., 1997), but now it is shown for genetic selection against decreased susceptibility to CM as well. For SCM, the estimated genetic correlations did not differ significantly.

Several studies have shown that the frequency of cases of mastitis is much greater in the first part of the lactation than in the second part (Emanuelson et al., 1988; Barkema et al., 1998). Therefore, the hypothesis was that SCC in the first half of the lactation is more informative as a mastitis indicator than SCC including the second half of the lactation. Slightly greater genetic correlations were indeed estimated for CM with SCC in the first half of lactation (SCS150) than in the second half of lactation (SCS151-400) in both data sets. Emanuelson et al. (1988) reported similar results in Swedish data, and De Haas et al. (2002) have reported this in other Dutch data. For genetic selection, it is beneficial to reduce the period of collecting sufficient data as much as possible, so that information becomes available sooner and reliable genetic selection can occur at an earlier age. For SCM, greater genetic correlations were estimated with SCC averaged over long lactations ( $\geq 350$ DIM) than over short lactations ( $\leq 150$ DIM). This seemed to suggest that selection for lower SCC, especially in late lactation, would decrease the frequency of SCM. This, however, can also be an artifact of the definition of SCM. A first case of SCM can only be assigned after at least 3 testday recordings. Knowing that SCC in the first 14 DIM was generally above the threshold levels (De Haas et al., 2002), and the average interval between 2 testdays was $28 \mathrm{~d}$, theoretically a first case of SCM could not be recorded before 70 DIM. Nevertheless, in practice, test-day SCC records that meet the threshold definitions of SCM mainly occur later (>100 DIM) in lactation. So, the longer the lactation, the more cases of SCM could be defined, which might explain the strong genetic correlation between SCM and SCS350 or SCS400. Partial genetic correlations also supported this result, although the same artifact could be valid here as well. Subclinical mastitis is associated with absence of a high SCC in early lactation (strong negative partial genetic correlations) and with presence of high SCC in late lactation (strong positive partial genetic correlations).

The positive genetic correlations suggested that selecting cows with low SCC might effectively reduce the occurrence of CM. A high SCC is indicative of an immune response to an IMI, and low SCC generally indicates freedom from such an infection. Cows with low SCC are therefore most interesting from an economic point of view. A cow with high SCC contributes to a high bulk tank SCC. Strict upper limits on bulk tank SCC are set in the Netherlands, with a financial penalty for milk delivered with an SCC that is too high. There is evidence that cows with low SCC produce a greater milk volume than cows with a high SCC (Koldeweij et al., 1999). For the bulk tank SCC, it is worthwhile to have many such cows, which is an extra stimulus to select cows with the lowest observed SCC.

However, an average does not fully describe the dynamic variation in SCC. The most desirable cow would respond very quickly to an IMI and then return to normal levels of SCC. Such a picture is not reflected in an average. Therefore, SCC was summarized in more biologically intuitive ways by analyzing patterns of peaks in SCC (De Haas et al., 2004) and interpreting excessive cell counts.

\section{SCC Patterns}

Presence of patterns of peaks in lactations has been shown to be phenotypically informative for pathogenspecific CM (De Haas et al., 2004). Lactations with $\mathrm{CM}$ and presence of the "no recovery pattern" (i.e., P_CONT) had high probabilities for contagious mastitis and low probabilities for environmental mastitis. The opposite, however, was true for lactations with presence of the "quick recovery pattern" (i.e., P_ENV; De Haas et al., 2004). Several studies under practical circumstances confirmed these results, as reported by Erskine et al. (1992) and Pyörälä et al. (1994) for P_ENV, and by Sheldrake et al. (1983) for P_CONT. Different parts of the cow's immune system (i.e., innate and adaptive immunity) are the major mechanism to eradicate IMI associated with either environmental or contagious pathogens (Schukken et al., 1997). Therefore, patterns in SCC might differ after cases of CM caused by environmental or contagious pathogens.

The Dutch breeding objective does not distinguish between contagious and environmental mastitis, but aims to decrease genetic susceptibility to $\mathrm{CM}$ (and SCM) overall. Therefore, focusing on reducing pathogen-specific cases of CM is not so relevant. The estimated heritabilities of the patterns of peaks in SCC were similar to the estimated heritabilities for $\mathrm{CM}$ and SCM, and strong genetic correlations were estimated between P_ALL and CM. This suggested that the proportion of cows with at least one case of CM could be reduced effectively by genetic selection for diminished presence of peaks in SCC. Positive and high partial genetic correlations were calculated between $\mathrm{CM}$ and patterns of peaks in SCC, particularly in subset B. 
This supported the suggestion that some additional information could be gained from the patterns of peaks for CM. In contrast, for SCM, the genetic correlations with the patterns of peaks in SCC were weaker than the genetic correlations with lactation-average SCS. This indicated that genetic selection for diminished presence of peaks in SCC would not affect the occurrence of SCM as effectively as selecting for lower lactation-average SCS. Compared with SCS335, presence of SCC peaks did not add information for SCM, as supported by the calculated negative partial genetic correlations between SCM and patterns of peaks in SCC. Therefore, to improve the overall udder health (i.e., both CM and SCM), several different SCC traits need to be combined in the udder health index.

\section{Excessive Cell Counts}

The idea behind emphasizing excessive test-day SCC was to attribute risks of IMI to cows. It relied on the hypothesis that higher SCC is linked to an IMI. The strong genetic correlations between "suspicion of IMI" and SCM confirmed this. In addition, a strong positive partial genetic correlation was calculated between SCM and "suspicion of IMI" in subset A. This indicated that presence of SCC $>150,000$ cells $/ \mathrm{mL}$ provided information for occurrence of SCM, additional to SCS335. Also, the duration of the longest streak of excessive test-day SCC was genetically strongly correlated with SCM. However, the calculated partial genetic correlations between these 2 traits were low. Therefore, "length of IMI" did not add much information compared with SCS335. Strong genetic correlations were estimated between SCS335 and the 4 traits that were defined based on excessive test-day SCC. This indicated that the current selection for lower SCS335 might already lessen the severity and shorten the duration of high SCC. Nash et al. (2002) also reported a similar result.

Cases of SCM could be better captured by identifying excessive cell count than by presence of patterns of peaks in SCC or by lactation-average SCC. Only SCC averaged over long-lasting lactations (350 or 400 DIM) showed similar strong genetic correlations with SCM. This can be confirmed by the current knowledge about the phenotypes of SCM. Subclinical mastitis can be identified by increased SCC and usually even repeated increased SCC recordings, with no clinical signs visible (Zadoks, 2002). When no clinical signs are visible, laboratory techniques such as bacteriological culture are needed to detect inflammation and infection.

\section{Genetic Selection}

The power of the current study is that the (co)variances were estimated in 2 independent data sets. Even though there was a wide range of genetic correlations between CM and SCM and several SCC traits estimated in this study, the estimates were all in the same direction. This supported the possibility of carrying these results on to the national database.

The most likely explanation of the differences in genetic correlations between $\mathrm{CM}$ and several SCC traits in subsets $\mathrm{A}$ and $\mathrm{B}$ is the different registration of $\mathrm{CM}$. In data set $\mathrm{A}$, the registration relied on the memory of a farmer at the 3- or 4-weekly milk recording. The registration in data set $\mathrm{B}$ was carried out daily in the herd's management information system, but subject to the interest of the farmer in recording mastitis. The registration in such system is a continuous flow of data, and therefore, in the long run, it would be suitable for use in the national breeding value estimation. This might also affect the different partial genetic correlations in the 2 data sets. For some traits (e.g., SCS250) the partial genetic correlations are 0.99 in one data set and 0 in the other. However, the estimated genetic correlations between CM and SCS250 differ between the 2 data sets, as well as the genetic correlations between CM and SCS335. These 2 differences result in more additional information of SCS250 in one data set than in the other.

Clinical and subclinical mastitis are not genetically the same traits. This was shown by the estimated genetic correlation between CM and SCM that did not show unity in either of the 2 subsets. In addition, different genetic correlations were estimated between CM and several SCC traits, and between SCM and these same SCC traits (i.e., the strongest genetic correlation for CM was estimated with another SCC trait rather than with SCM). A combination of different SCC traits might therefore be necessary in a final udder health index aiming to reduce genetic susceptibility for CM and SCM overall.

Further research is needed to determine which traits should be included in a selection index to improve overall udder health with genetic selection. A combination of different traits is probably best due to the range of genetic correlations that was estimated between SCC traits and CM or SCM, varying from 0.55 to 0.93 for $\mathrm{CM}$, and from 0.55 to 0.98 for SCM. However, more genetic correlations have to be estimated to be able to support the choice of SCC traits. For example, 1) the genetic correlations among the SCC traits within a subset and between the 2 subsets, 2) the genetic correlation between $\mathrm{CM}$ in subset $\mathrm{A}$ and CM in subset B, and 3) similar for SCM. The current study has already shown some very promising results for some of the alternative SCC traits, but further refinement of the SCC, CM, or SCM traits might improve the results. For example, analyzing parity-spe- 
cific CM and SCM instead of overall CM and SCM, may be a next step. The SCC trait "suspicion of IMI" may also be improved further. In the current study, this trait was defined as a binary trait with a threshold of 150,000 cells $/ \mathrm{mL}$, but the "suspicion of IMI" may not be straightforward. It is likely that it shifts gradually from 0 to $100 \%$ suspected as a continuous trait. Selection indices will have to be calculated with different combinations of the SCC traits to test what combination of traits will result in the greatest accuracy and most genetic progress.

\section{CONCLUSIONS}

A wide range of genetic correlations between udder health traits and several SCC traits was estimated in this study, and results were shown for some of the alternative SCC traits. The greatest genetic correlation for SCM was estimated with SCS151-400 in both subsets. Genetic correlations for CM were not as high, and differed in the 2 subsets (i.e., SCS250 and P_ENV in subsets A and B, respectively). Further work to refine the definitions of the SCC, CM, and SCM traits might improve the results. Selection index calculations will have to be carried out to identify the most informative SCC traits to be included in an index to reduce overall genetic susceptibility for CM and SCM.

\section{ACKNOWLEDGMENTS}

The farmers are gratefully acknowledged for providing information on occurrence of cases of clinical mastitis. This study is part of the 5-yr mastitis program of the Dutch Udder Health Center and was financially supported by the Dutch Dairy Board. The authors thank Theo Lam and Otlis Sampimon for their fruitful discussions and useful comments on the manuscript. Two anonymous reviewers are acknowledged for their valuable contributions to improve the manuscript.

\section{REFERENCES}

Barkema, H. W., Y. H. Schukken, T. J. G. M. Lam, M. L. Beiboer, H. Wilmink, G. Benedictus, and A. Brand. 1998. Incidence of clinical mastitis in dairy herds grouped in three categories by bulk milk somatic cell counts. J. Dairy Sci. 81:411-419.

Calus, M. P. L., J. J. Windig, and R. F. Veerkamp. 2005. Associations among descriptors of herd management and phenotypic and genetic levels of health and fertility. J. Dairy Sci. 88:2178-2189.

De Haas, Y., H. W. Barkema, and R. F. Veerkamp. 2002. Effect of pathogen-specific clinical mastitis on the lactation curve for somatic cell count. J. Dairy Sci. 85:1314-1323.

De Haas, Y., Y. H. Schukken, H. W. Barkema, and R. F. Veerkamp. 2003. Genetic associations for pathogen-specific clinical mastitis and somatic cell count patterns. Anim. Sci. 77:187-195.

De Haas, Y., R. F. Veerkamp, H. W. Barkema, Y. T. Gröhn, and Y. H. Schukken. 2004. Associations between pathogen-specific clinical mastitis and somatic cell count patterns. J. Dairy Sci. $87: 95-105$.
Detilleux, J. C., P. Leroy, and D. Volckaert. 1997. Alternative use of somatic cell counts in genetic selection for mastitis resistance. Interbull Bull. 15:34-44.

Dohoo, I. R., and K. E. Leslie. 1991. Evaluation of changes in somatic cell counts as indicators of new intramammary infections. Prev. Vet. Med. 10:225-237.

Emanuelson, U., B. Danell, and J. Philipsson. 1988. Genetic parameters for clinical mastitis, somatic cell counts, and milk production estimated by multiple-trait restricted maximum likelihood. J. Dairy Sci. 71:467-476.

Erskine, R. J., R. C. Wilson, M. G. Riddell, J. W. Tyler, H. J. Spears, and B. S. Davis. 1992. Intramammary administration of gentamicin as treatment for experimentally induced Escherichia coli mastitis in cows. Am. J. Vet. Res. 53:375-381.

Fox, L. K., and J. M. Gay. 1993. Contagious Mastitis. Vet. Clin. North Am. Food Anim. Pract. 9:475-487.

Gengler, N., and P. Mayeres. 2003. Use of a weighted random regression test-day model to better relate observed somatic cell score to mastitis infection likelihood. Interbull Bull. 31:92-96.

Gilmour, A. R., B. J. Gogel, B. R. Cullis, and R. Thompson. 2006. ASREML User Guide Release 2.0. VSN International Ltd., Hemel Hempstead, UK.

Heringstad, B., Y. M. Chang, D. Gianola, and G. Klemetsdal. 2003. Genetic analysis of longitudinal trajectory of clinical mastitis in first-lactation Norwegian cattle. J. Dairy Sci. 86:2676-2683.

Heringstad, B., A. Karlsen, G. Klemetsdal, and J. Ruane. 1997. Preliminary results from a genetic analysis of clinical mastitis data. Interbull Bull. 15:45-49.

Heuven, H. C. M. 1987. Diagnostic and genetic analysis of mastitis field data. PhD Thesis. University of Wisconsin, Madison.

Koldeweij, E., U. Emanuelson, and L. Janson. 1999. Relation of milk production loss to milk somatic cell count. Acta Vet. Scand. 40:47-56

Lam, T. J. G. M., Y. H. Schukken, F. J. Grommers, J. A. H. Smit, and A. Brand. 1993. Within-herd and between-herd variation in diagnosis of clinical mastitis in cattle. J. Am. Vet. Med. Assoc. 202:938-942.

Lam, T. J. G. M., J. H. Van Vliet, Y. H. Schukken, F. J. Grommers, A. Van Velden-Russcher, H. W. Barkema, and A. Brand. 1997. The effect of discontinuation of postmilking teat disinfection in low somatic cell count herds. II. Dynamics of intramammary infections. Vet. Q. 19:47-53.

Lowry, R. 2007. Web site for statistical computation, Chapter 3a. http://faculty.vassar.edu/lowry/ch3a.html Accessed July 27, 2007.

Mark, T., W. F. Fikse, E. Emanuelson, and J. Philipsson. 2002. International genetic evaluations of Holstein sires for milk somatic cell and clinical mastitis. J. Dairy Sci. 85:2384-2392.

Miglior, F., B. L. Muir, and B. J. Van Doormaal. 2005. Selection indices in Holstein cattle of various countries. J. Dairy Sci. 88:1255-1263.

Mrode, R. A., and G. J. T. Swanson. 1996. Genetic and statistical properties of somatic cell count and its suitability as an indirect means of reducing the incidence of mastitis in dairy cattle. Anim. Breed. Abstr. 64:847-857.

Nash, D. L., G. W. Rogers, J. B. Cooper, G. L. Hargrove, and J. F. Keown. 2002. Relationships among severity and duration of clinical mastitis and sire transmitting abilities for somatic cell score, udder type traits, productive life, and protein yield. J. Dairy Sci. 85:1273-1284.

NRS (Dutch Dairy Association). 2005. Manual NRS, Chapter E-18, pp. 1-8, http://www.nrs.nl/cms/servlet/dbupload?id=3537 Accessed July 27, 2007.

Pyörälä, S., L. Kaartinen, H. Kack, and V. Rainio. 1994. Efficacy of two therapy regimens for treatment of experimentally induced Escherichia coli mastitis in cows. J. Dairy Sci. 77:453-461.

Reents, R., J. Jamrozik, L. R. Schaeffer, and J. C. M. Dekkers. 1995. Estimation of genetic parameters for test day records of somatic cell score. J. Dairy Sci. 78:2847-2857.

Rupp, R., and D. Boichard. 2000. Relationship of early first lactation somatic cell count with risk of subsequent first clinical mastitis. Livest. Prod. Sci. 62:169-180. 
Schepers, A. J., T. J. G. M. Lam, Y. H. Schukken, J. B. M. Wilmink, and W. J. A. Hanekamp. 1997. Estimation of variance components for somatic cell counts to determine thresholds for uninfected quarters. J. Dairy Sci. 80:1833-1840.

Schukken, Y. H., T. J. G. M. Lam, and H. W. Barkema. 1997. Biological basis for selection on udder health. Interbull Bull. 15:27-33.

Sheldrake, R. F., R. J. T. Hoare, and G. D. McGregor. 1983. Lactation stage, parity, and infection affecting somatic cells, electrical conductivity, and serum albumin in milk. J. Dairy Sci. 66:542-547.

Smith, K. L., and J. S. Hogan. 1993. Environmental Mastitis. Vet. Clin. North Am. Food Anim. Pract. 9:489-498.

Van den Borne, B. H. P., G. Van Schaik, G. De Jong, and T. J. G. M. Lam. 2006. Determination of a definition of subclinical mastitis incidence based on somatic cell counts in the Netherlands. Proc. 11th Int. Symp. Vet. Epidemiol. Econ. (ISVEE), Cairns, Australia. ISVEE 11:609-611.

Wegner, T. N., J. D. Schuh, F. E. Nelson, and G. H. Stott. 1976. Effect of stress on blood leukocyte and milk somatic cell counts in dairy cows. J. Dairy Sci. 59:949-956.

Wever, P., and U. Emanuelson. 1989. Effects of systematic influences and intramammary infection on differential and total somatic cell counts in quarter milk samples from dairy cows. Acta Vet. Scand. 30:465-474.

Zadoks, R. N. 2002. Molecular and mathematical epidemiology of Staphylococcus aureus and Streptococcus uberis mastitis in dairy herds. PhD Thesis. Utrecht University, Utrecht, the Netherlands. 